\title{
Estudo da influência do sombreamento arbóreo nos índices de conforto térmico na cidade de Cuiabá - MT
}

\author{
Study of the influence of tree shade on thermal comfort indexes in the city of \\ Cuiabá - MT
}

KARYN FERREIRA ANTUNES RIBEIRO ${ }^{1}(*)$

MARCOS DE OLIVEIRA VALIN JR ${ }^{2}$

FLÁVIA MARIA DE MOURA SANTOS ${ }^{3}$

MARTA CRISTINA DE JESUS ALBUQUERQUE NOGUEIRA ${ }^{4}$

JOSÉ DE SOUZA NOGUEIRA ${ }^{5}$

\section{Resumo}

A arborização urbana é determinante no microclima local, pois atua como regulador térmico por meio dos processos fisiológicos como evapotranspiração. Desta forma afetando diretamente no conforto térmico e na qualidade de vida dos habitantes. $\mathrm{O}$ objetivo desta pesquisa foi estudar o sombreamento arbóreo de duas espécies: oiti (Licania tomentosa) e mangueira (Mangifera indica), analisando os índices de conforto térmico nos períodos quente-seco e quente-úmido na cidade de Cuiabá-MT, em três horários do dia: 8h, 14 h e 20h, por meio de questionários de percepção e preferência de sensação térmica. Como referencial foi utilizado um local sem sombreamento arbóreo. Foram determinados os índices de conforto térmico através do PMV (Voto Médio Estimado) e do PET (Temperatura Fisiológica Equivalente) utilizando o software RayMan. Também foi analisado o IAF (Índice de Área Foliar) das espécies. Quanto a análise dos índices de conforto térmico, não houveram variações expressivas para os diferentes sexos calculados sendo que apenas no período noturno (20h) os valores do PET e PMV foram satisfatórios, alcançando a faixa de conforto térmico, em ambos os índices neste horário. Foi possível observar que no período quente-úmido, nos três horários analisados, os usuários sentiram calor, mas responderam estarem confortáveis,

1 Doutoranda; Física Ambiental; Universidade Federal de Mato Grosso, UFMT, Brasil; Professora no Instituto Federal de Educação, Ciência e Tecnologia de Mato Grosso (2012 - atualmente); Instituto Federal de Educação, Ciência e Tecnologi, CAMPUS CUIABÁ - OCTAYDE JORGE DA SILVA; Endereço: Rua Zulmira Canavarros, Centro Norte. CEP: 78005200 - Cuiabá, MT - Brasil E-Mail: karyn.ribeiro@cba.ifmt.edu.br $\left(^{*}\right)$ Autor para correspondências

2 Doutorando; Física Ambiental; Universidade Federal de Mato Grosso, UFMT, Brasil; Professor do Ensino Básico, Técnico e Tecnológico do Instituto Federal de Educação Ciência e Tecnologia de Mato Grosso - IFMT - Campus Octayde Jorge da Silva, Cuiabá; Instituto Federal de Educação Ciência e Tecnologia de Mato Grosso, Campus Cuiabá; Endereço: Rua Zulmira Canavarros, no 95,Centro. CEP: 78005390 - Cuiabá, MT - Brasil E-Mail: marcos.valin@cba. ifmt.edu.br

3 Dra.; Física Ambiental; Universidade Federal de Mato Grosso, UFMT, Brasil; Professora Adjunto III do quadro efetivo no Departamento de Arquitetura e Urbanismo, Faculdade de Arquitetura, Engenharia e Tecnologia, Universidade Federal de Mato Grosso; Endereço: Av. Fernando Corrêa da Costa, 2367 - Boa Esperança, Cuiabá - MT, CEP: 78060-900; E-Mail: flavia_mms@hotmail.com

4 Dra.; Engenharia Civil; Universidade de São Paulo, USP, Brasil; Professora Titular do Departamento de Arquitetura e Urbanismo/ FAET/ UFMT; Universidade Federal de Mato Grosso, Faculdade de Arquitetura Engenharia e Tecnologia, Departamento de Arquitetura e Urbanismo. Av. Fernando Corrêa da Costa n 2367, Boa Esperança-Coxipó. CEP: 78060900 - Cuiabá, MT - Brasil E-Mail: mcjanp@gmail.com

5 Dr.; Química; Universidade de São Paulo, USP, Brasil; Professor Titular da Universidade Federal de Mato Grosso, Bolsista Produtividade CNPq - nível 1A e Coordena o Mestrado e Doutorado em Física Ambiental; Endereço: Universidade Federal de Mato Grosso, Instituto de Física, Programa de Pós-Graduação em Física Ambiental. AV. FERNANDO CORREA, 2367, Boa Esperança. CEP:78060900 - Cuiabá, MT - Brasil E-Mail: nogueira@ufmt.br

\begin{tabular}{llllll}
\hline Ambiência & Guarapuava (PR) & v.14 n.2 & p. 300-314 & Maio/Ago 2018 & ISSN $1808-0251$
\end{tabular}


indicando o fato de estarem aclimatados com as condições do clima na região. No período quente-seco, observa-se menor resistência dos usuários ao rigor climático pelo calor, demonstrando-se desconfortáveis com a condição climática do período. Os resultados demostraram melhores desempenhos térmicos nas áreas com sombreamento arbóreo, reforçando a importância da arborização nas cidades para proporcionar melhor conforto térmico aos usuários.

Palavras-chave: Arborização, PET, PMV.

\section{Abstract}

The urban afforestation is determinant in the local microclimate, as it acts as a thermal regulator through the physiological processes like evapotranspiration. In this way directly affecting the thermal comfort and quality of life of the inhabitants. The objective of this research was to study the arboreal shading of two species: oiti (Licania tomentosa) and mango tree (Mangifera indica), analyzing the thermal comfort indices in the hot-dry and hot-humid periods in the city of Cuiabá-MT, in three schedules Of the day: $8 \mathrm{am}, 2 \mathrm{pm}$ and $8 \mathrm{pm}$, through questionnaires of perception and preference of thermal sensation. As a reference, a site without arboreal shading was used. The thermal comfort indexes were determined through the PMV (Estimated Average Voting) and the PET (Equivalent Physiological Temperature) using RayMan software. The IAF (Leaf Area Index) of the species was also analyzed. As for the analysis of the thermal comfort indexes, there were no significant variations for the different sexes calculated, and only in the night time (20h) the PET and PMV values were satisfactory, reaching the thermal comfort range, in both indices at this time. It was possible to observe that in the hot-humid period, in the three analyzed schedules, the users felt warm, but responded that they were comfortable, indicating that they were acclimatized to the climatic conditions in the region. In the hot-dry period, there is less resistance of the users to the climatic rigor due to the heat, proving to be uncomfortable with the climatic condition of the period. The results demonstrated better thermal performance in areas with tree shade, reinforcing the importance of afforestation in cities to provide better thermal comfort to users.

Key words: Arborization, PET, PMV.

\section{Introdução}

A falta de planejamento arbóreo nas cidades é preocupante, pois seus benefícios são determinantes na qualidade de vida dos habitantes, principalmente em cidades que possuem temperaturas elevadas o ano todo. A vegetação arbórea por suas características naturais proporciona muitas vantagens (CALLEJAS et al.,2014), como por exemplo, a interceptação da radiação solar sobre a superfície (NOWAK et al., 2000), redução da poluição do ar (ORTOLANI; VITALE, 2016), obstáculo aos ruídos e aos ventos mais intensos (CALLEJAS et al., 2014), dentre outros (GOMES \& SOARES, 2003; TAKÁCS et al., 2016).

A partir do conhecimento das variáveis ambientais e pessoais é possível proceder à avaliação do conforto térmico. Existem vários índices de conforto térmico, entre eles destaca-se o índice 
PMV e o PET (KULKA, 2014). Conforme Moreno (2006), o PMV é obtido a partir das variáveis ambientais (temperatura, umidade relativa, temperatura radiante média e velocidade do ar) e das variáveis pessoais (taxa de metabolismo e resistência térmica das vestimentas). Estudos recentes indicam que o PET é a escolha mais adequada para avaliar as condições de conforto térmico dos ambientes ao ar livre, devido à consideração da inter-relação entre balanço de energia do corpo humano e de radiação de onda curta (NINCE, 2013).

Foram estudadas neste artigo o sombreamento de duas espécies: oiti e mangueira. Foram escolhidas, pois são abundantes e tipicamente utilizadas na arborização urbana na região. Conforme Almeida Júnior (2005), o oiti é amplamente utilizado na arborização em Mato Grosso, por sua excepcional adaptação as condições locais e devido às alterações microclimáticas positivas em função do sombreamento promovido. Já a mangueira é uma espécie que tem se destacado na arborização da cidade de Belém/PA, por causa de suas caraterísticas como: copa larga, muita resistência às intempéries (chuvas, ventos, etc.), além de proporcionar um microclima agradável com formação de túneis verdes nas ruas e avenidas da cidade, gerando sensação de bem-estar (LOUREIRO E BARBOSA, 2010; SILVA et al. 2015).

Foi analisado também o IAF (Índice de Área Foliar), que constitui um dos principais parâmetros biofísicos e estruturais da vegetação e é definido como a área foliar total por unidade de área do solo (CALLEJAS et al., 2014). O IAF está diretamente ligado na interceptação e absorção da luz na copa, logo correlacionado com a qualidade do sombreamento arbóreo (BONAN, 1997). Segundo Yang et al. (1999), as copas densas possuem IAF alto e menor fluxo de calor no solo, desta forma, constitui um importante parâmetro na avaliação da qualidade da arborização.

O objetivo desta pesquisa foi estudar o sombreamento arbóreo de duas espécies: mangueira e oiti, analisando os índices de conforto térmico dos usuários nos períodos quente-seco e quenteúmido na cidade de Cuiabá-MT, em três horários do dia: 8 h, 14h e 20h, por meio de questionários de percepção e preferência de sensação térmica.

\section{Material e Métodos}

\section{Área de estudo}

Este estudo foi desenvolvido na cidade de Cuiabá - MT (Figura 1) no campus da UFMT, este local foi escolhido por apresentar as duas espécies estudadas em ambulância.

O clima de Cuiabá é do tipo Aw, segundo a classificação de Köppen, identificado prioritariamente pela temperatura, apresentando duas estações bem definidas: uma seca, de abril a outubro, e outra chuvosa, de novembro a março, com médias entre 28 e $32^{\circ} \mathrm{C}$ (ALVES; BIUDES, 2012). 


\section{Figura 1 - Campus UFMT- Cuiabá com diferentes superfícies}

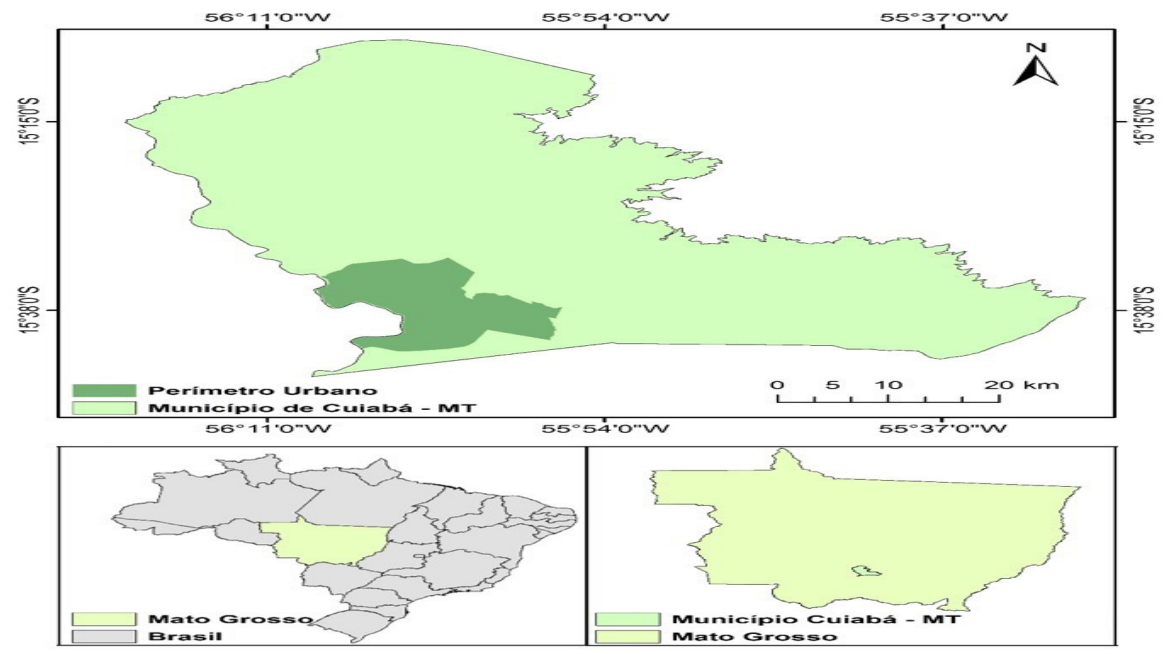

O campus está localizado na Av. Fernando Correa da Costa, e apresenta uma área de 74 hectares, sendo caracterizado por um ambiente heterogêneo (Figura 2), com diferentes superfícies urbanas de uso e ocupação do solo (CAMPOS NETO, 2007).

\section{Figura 2 - Campus UFMT- Cuiabá com diferentes superfícies}

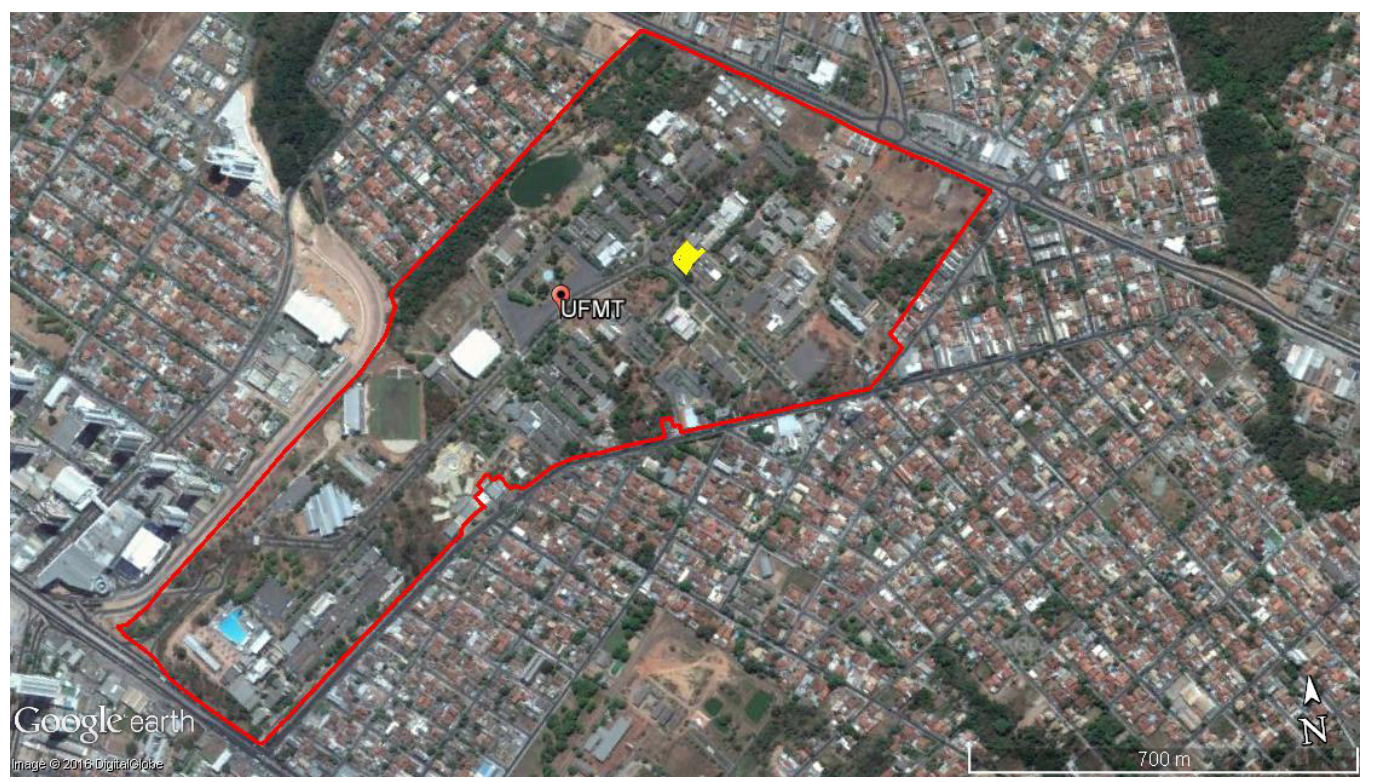

Fonte: Google Earth (2015)

Pode-se destacar os locais de áreas verdes (bosques) que são utilizados pelos estudantes e visitantes, para esporte e lazer. O zoológico contém uma lagoa e vegetação. Campo de futebol possui elevada área aberta com vegetação rasteira (gramado) circundado por uma pista de corrida. Áreas expostas (solo nu) sem presença de vegetação. Como exemplos de áreas impermeabilizadas tem-se estacionamentos, vias pavimentadas, faculdades e institutos (ALVES; BIUDES, 2012). 


\section{Dados de coleta e equipamentos utilizados}

Os dados de temperatura do ar e umidade do ar foram coletados durante os três horários do dia (manhã, tarde e noite) às $08 \mathrm{~h}, 14 \mathrm{~h}$ e $20 \mathrm{~h}$. No período quente-úmido, as coletas foram realizadas no mês de março e abril e no período quente-seco foi no mês de agosto.

Os equipamentos utilizados nesta pesquisa estão apresentados na Tabela 1.

\section{Tabela 1 - Equipamentos utilizados com suas principais características}

\begin{tabular}{ccc}
\hline Equipamentos & Modelo & Características \\
\hline $\begin{array}{c}\text { Termo-higro-anemômetro } \\
\text { digital portátil }\end{array}$ & $\begin{array}{c}\text { THAR-185H, marca } \\
\text { Instrutherm }\end{array}$ & $\begin{array}{c}\text { Temperatura na faixa de } 0{ }^{\circ} \mathrm{C} \text { a } 50{ }^{\circ} \mathrm{C} \mathrm{e} \\
\text { umidade de } 10 \% \text { a } 95 \% \mathrm{UR} \text {, e funciona } \\
\text { com uma bateria de } 9 \mathrm{~V} .\end{array}$ \\
Ceptômetro & AccuPAR Lp-80 & $\begin{array}{c}80 \text { sensores sensíveis à radiação PAR } \\
\text { (Radiação Fotossinteticamente Ativa) }\end{array}$ \\
\hline
\end{tabular}

Foi utilizado um abrigo de tubo de PVC para proteger o termo-higro-anemômetro durante a coleta de dados, Cox (2008), Franco (2010) e Santos et al. (2013) foram alguns dos pesquisadores que utilizaram esse mesmo tipo de abrigo nos seus estudos.

As medições do IAF foram realizadas sob as copas das espécies arbóreas em condições de céu limpo, próximo às $12 \mathrm{~h}$, sendo que, foram coletadas duas medições e realizado a média delas como o resultado final.

Os questionários foram realizados em conjunto com a coleta da temperatura do ar e umidade relativa do ar.

\section{Índice de conforto térmico e questionário}

As definições dos níveis de conforto térmico foram expressas através da temperatura PET e PMV, calculados através do software RayMan versão 1.2. Para a realização do cálculo dos índices, fez-se necessário inserir dados na interface do software RayMan versão 1.2 (2000) como: Data (dia/mês/ano), Dia do ano, Hora local (h), Temperatura do ar $\left({ }^{\circ} \mathrm{C}\right)$, Umidade relativa do ar (\%), Velocidade do vento $\left(\mathrm{m} . \mathrm{s}^{-1}\right)$ e Radiação global $\left(\mathrm{W} / \mathrm{m}^{2}\right)$, coordenadas geográficas locais (latitude, longitude e altitude) e fuso-horário (UTC+h). O programa foi desenvolvido por Andreas Matzarakis e é de domínio público, apenas para uso pessoal e pesquisas acadêmicas, através de contato por correio eletrônico (http://www.mif.uni-freiburg.de/RayMan).

A escala de sensação térmica do PMV apresenta uma linha graduada que varia de -3 a +3 que permite uma avaliação termo-ambiental com temperaturas reduzidas ou elevadas. $\mathrm{O}$ conforto térmico se enquadra no intervalo numérico de $-0,5$ e $+0,5$, para ambientes frios e quentes, respectivamente, (OLIVEIRA et al., 2010).

Foram utilizados os dados obtidos por um termo-higrômetro (temperatura e umidade do ar) registrados nas diferentes situações (Licania tomentosa, Mangifera indica e sem sombreamento) e horários (manhã, tarde e noite) para preencher a interface do programa. Sobre as características físicas dos entrevistados, adotou-se o mesmo apresentado por Nince (2013):

Para pedestres masculinos: altura de $1,70 \mathrm{~m}$, peso de $70 \mathrm{~kg}$ e pedestres femininos: altura de $1,60 \mathrm{~m}$ peso de $60 \mathrm{~kg}$ e para ambos os sexos: vestimenta de $0,5 \mathrm{clo}$ que corresponde a pessoa usando vestimenta leve de verão, ou seja, roupas intimas, calças longas leves, camisas abertas no pescoço 
com mangas curtas, meias e calçados leves e atividade de caminhada lenta com taxa metabólica de $135 \mathrm{~W}$, ou seja, pessoa andando a $4 \mathrm{~km} / \mathrm{h}$.

$\mathrm{O}$ índice PET tem, por definição, o mesmo valor da temperatura do ar de um ambiente padrão, que propicia a mesma quantidade de calor armazenado ou mesma temperatura superficial do corpo humano sob a ação conjunta das variáveis ambientais consideradas. O clima interno do ambiente padrão assume os seguintes valores: Temperatura radiante média $\left(\operatorname{Trm},{ }^{\circ} \mathrm{C}\right)$ igual à temperatura do ar $\left(\mathrm{Ta},{ }^{\circ} \mathrm{C}\right)$; Velocidade do ar $(\mathrm{V})$ igual a $0,1 \mathrm{~m} / \mathrm{s}$; Pressão de vapor d'água (pa) igual a $12 \mathrm{hPa}$; Umidade relativa do ar (UR) a $50 \%$ e temperatura do ar (Ta) a $20^{\circ} \mathrm{C}$ (que leva aproximadamente $12 \mathrm{hPa}$ ).

O questionário utilizado nessa pesquisa foi o modelo desenvolvido por Nince (2013), contendo perguntas pessoais como: cor da roupa, idade, sexo, atividade, exposição ao sol, se era natural de Cuiabá, em caso negativo há quantos anos morando em Cuiabá. E as perguntas sobre a percepção e preferência de sensação térmica adaptado de Monteiro e Alucci (2010). Os questionários foram realizados apenas nos locais sombreados, pois era o local com maior circulação de pessoas. As pessoas para respondem aos questionários foram escolhidas forma aleatória.

\section{Resultados e Discussões}

\section{Temperatura e umidade relativa do ar}

Conforme a Figura 3, as medições de temperatura do ar registradas no horário da manhã não apresentaram diferenças significativas, as temperaturas variaram entre $27,5^{\circ} \mathrm{C}-28,6^{\circ} \mathrm{C}$, independente do cenário (oiti / mangueira / sem arborização) e do período (quente-seco / quente-úmido). Segundo Maciel, Nogueira e Nogueira (2011), no período matutino os pontos de coleta ainda estão começando a receber a radiação solar, portanto, as diferenças de temperatura devido à incidência solar ainda não são expressivas. Já a umidade relativa do ar neste horário teve o mesmo comportamento que a temperatura do ar quando alterou o cenário, porém apresentou diferenças quando mudou de período, indicando a sazonalidade da região.

\section{Figura 3 - Temperatura e umidade relativa do ar nos diferentes horários, cenários e períodos}
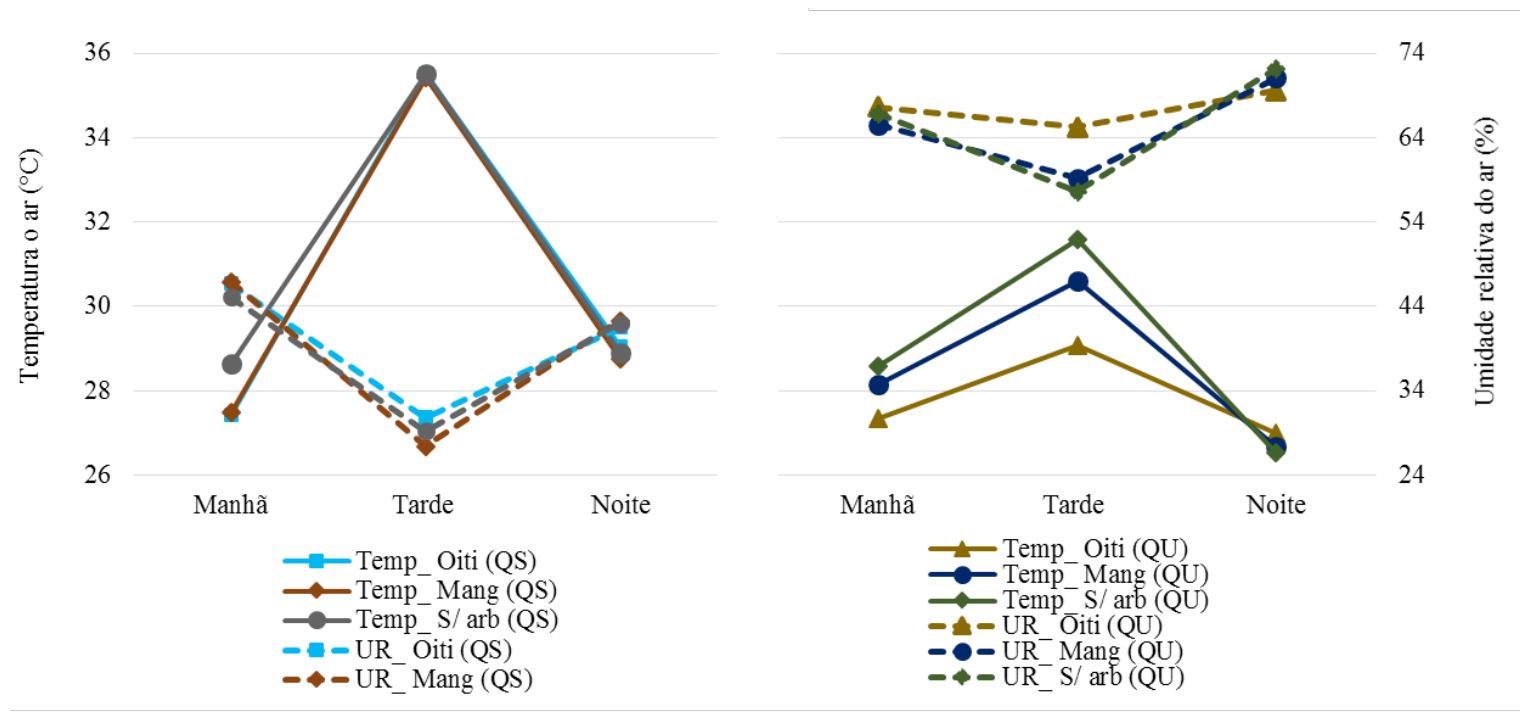
No período da tarde ocorreram as maiores variações das medições de temperatura do ar e umidade relativa. Ao comparar as temperaturas e umidades registradas entre período quente-seco (QS) e período quente-úmido (QU), obtém-se as seguintes diferenças: 6,43드-34,73\% (oiti), de $4,81^{\circ} \mathrm{C} /-31,73 \%$ (mangueira) e de $3,92^{\circ} \mathrm{C} /-28,33 \%$ (sem arborização), sendo que o período seco apresenta maiores valores de temperatura e menores valores de umidade relativa. Segundo Maciel, Nogueira e Nogueira (2011), no horário das 14h, todas as maiores temperaturas médias foram registradas nos locais com características predominantemente urbanas (materiais com baixo albedo, bastante massa construída e pouca -ou nenhuma, em alguns casos - vegetação).

Segundo Pereira (2002) a temperatura do ar é um dos efeitos mais importantes da radiação solar. Valin Jr et al. (2015) afirma que a variação temporal e espacial da temperatura do ar é condicionada pelo balanço de energia na superfície, de modo que as variações microclimáticas desta variável são determinadas principalmente pela cobertura do terreno.

No horário da noite as variações nas medições de temperatura do ar entre os períodos foram menores que as umidades, as diferenças foram de $2,07^{\circ} \mathrm{C} /-28,15 \%$ (oiti), de 2,09 ${ }^{\circ} \mathrm{C} /-28,81 \%$ (mangueira) e de 2,38 $\mathrm{C} /-30,17 \%$ (sem arborização). Segundo Maciel, Nogueira e Nogueira (2011), no horário da noite, a porção urbana recebeu radiação proveniente do sol durante todo o dia e, após o pôr-do-sol inicia então o processo de remissão desta energia absorvida, de acordo com as características dos materiais constituintes.

\section{Índice de área foliar (IAF)}

As duas espécies analisadas obtiveram o índice de área foliar (IAF) próximos conforme a Tabela 2.

\section{Tabela 2 - Resultado do IAF}

\begin{tabular}{cc}
\hline Espécie & IAF $\left(\mathbf{~}^{\mathbf{2}} \mathbf{m}^{-2}\right.$ ) \\
\hline Oiti (Licania tomentosa) & 4,82 \\
Mangueira (Mangifera indica) & 4,52 \\
\hline
\end{tabular}

Segundo Callejas et al. (2014) o IAF pode ser utilizado na avaliação da qualidade da arborização, pois constitui um dos principais parâmetros biofísicos e estruturais da vegetação e é definido como a área foliar total por unidade de área do solo $\left(\mathrm{mm}^{-2}\right)$.

De acordo com Bonan (1997) apud Oliveira (2011), o sombreamento das árvores pode agir para esfriar a atmosfera por baixo, simplesmente por interceptar a radiação solar. O Índice de área foliar é um dos principais parâmetros biofísicos e estruturais da vegetação, pois por meio dele quantifica esta interceptação.

Em estudo realizado por Callejas et al. (2011) em escolas na cidade de Cuiabá, os resultados apontaram a existência de uma relação direta entre a melhoria das condições de conforto térmico, com a diminuição da temperatura do ar e a elevação da umidade abaixo das copas das árvores a medida que o IAF se eleva.

Segundo Callejas et al. (2012) quanto maior o valor do IAF, maior é interceptação da radiação solar e maior também será seu sombreamento, com isso favorecendo o resfriamento da atmosfera sob as mesmas. Portanto, podendo ser um parâmetro importante na avaliação da qualidade da arborização em termos de melhoria das condições bioclimáticas dos ambientes.

Durante e Nogueira (2013) estudando o sombreamento arbóreo em ambiente interno e externo, concluíram que as copas das árvores proporcionam um efeito oásis no período diurno e 
um efeito barreira (de abrigo) no período noturno, dependendo sobretudo do porte e da arquitetura foliar. Das espécies estuda, a mangueira, com IAF de $10,1 \mathrm{~m}^{2} \mathrm{~m}^{-2}$ proporcionou maior atenuação da temperatura sob a copa do que da espécie oiti, com IAF de $7,4 \mathrm{~m}^{2} \mathrm{~m}^{-2}$, tendo, ambas as unidades arbóreas de sombreamento, grande porte.

\section{Índice de conforto (PET e PMV)}

Foram calculados no software RayMan o PET e o PMV para os sexos femininos e masculinos, e foi observado que não houve variações expressivas para os diferentes sexos (Figura 4 e Figura 5).

Utilizando a tabela do índice PET calibrado por Monteiro (2008) e o PMV por Matzarakis et al. (1999), a faixa de 18 - 26 do $\operatorname{PET~}\left({ }^{\circ} \mathrm{C}\right)$ como percepção térmica "neutra ou confortável" e de 0,5 - 1,5 (PMV) como "nenhum stress térmico a ligeiro stress ao calor", ocorreu somente no horário noturno e nos dois períodos. Portanto alcançar a faixa de conforto térmico em Cuiabá só é possível no horário noturno, Nince et al. (2014) observou o mesmo resultado.

\section{Figura 4 - PET e PMV no período quente-úmido}
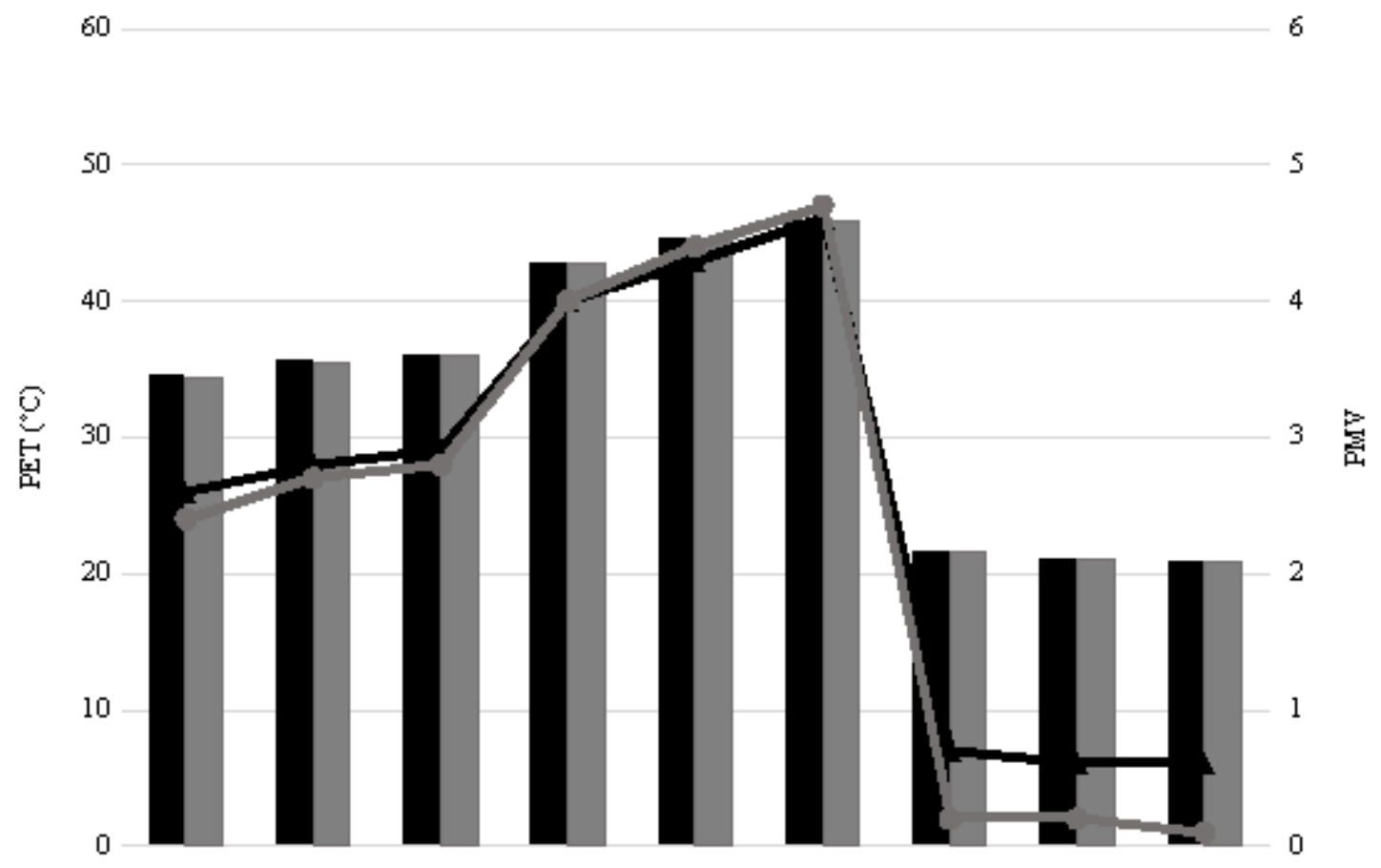

No horário da tarde nos dois períodos ocorreram as maiores $\mathrm{PET}\left({ }^{\circ} \mathrm{C}\right)$ e PMV, com máxima de PET $\left({ }^{\circ} \mathrm{C}\right) 45,9^{\circ} \mathrm{C}$ para o local sem sombreamento para o sexo masculino no período quenteúmido e de $50,5^{\circ} \mathrm{C}$ para o período quente-seco, resultando como percepção térmica "muito calor". Os valores máximos de PMV foram de 4,7 para o local sem sombreamento para o sexo feminino no período quente-úmido e de 5,6 no período quente-seco, resultando como "forte stress ao calor a extremo stress ao calor". 


\section{Figura 5 - PET e PMV no período quente-seco}

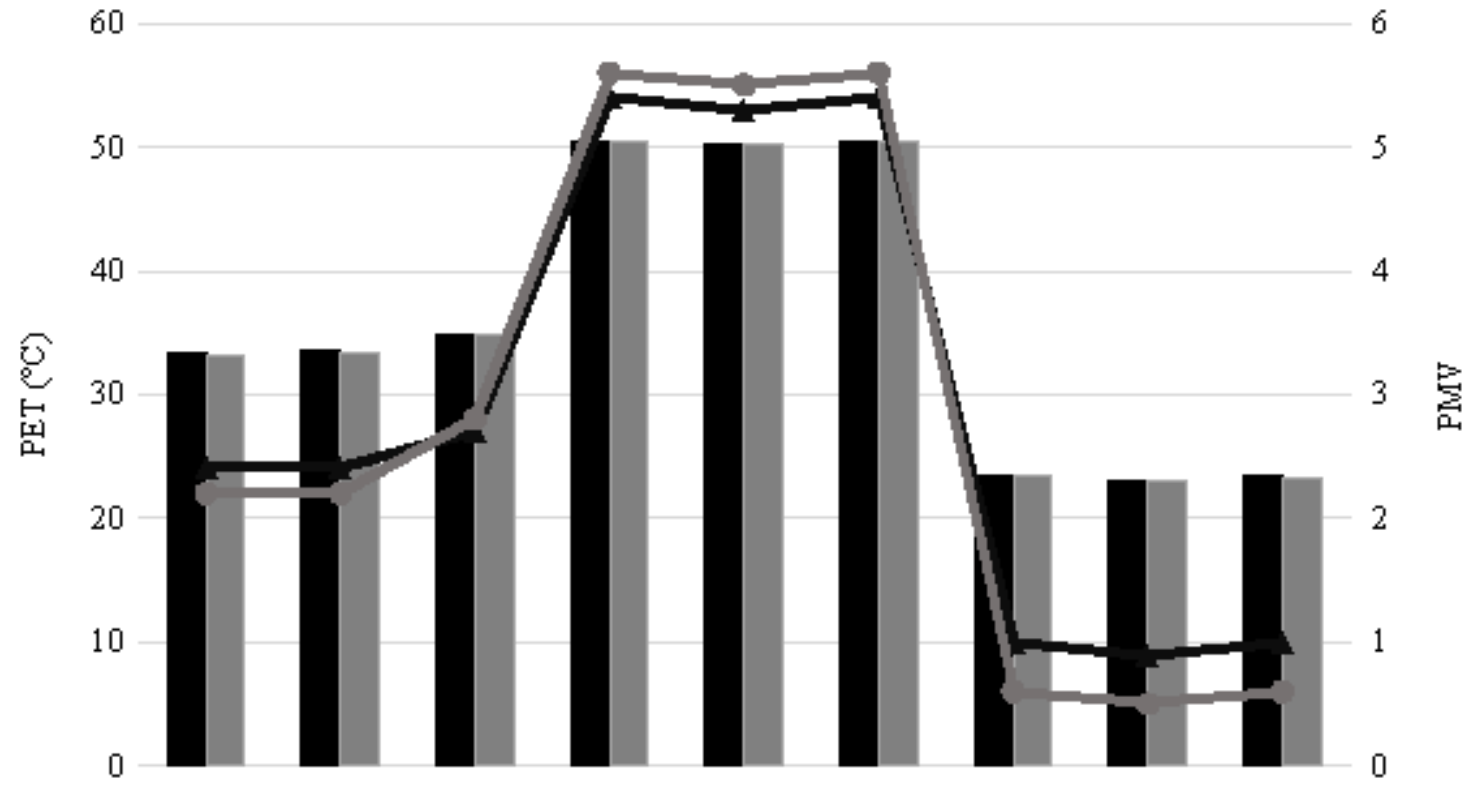

$\mathrm{Na}$ parte da manhã o $\operatorname{PET}\left({ }^{\circ} \mathrm{C}\right)$ no período quente-úmido foi maior que no período quente-seco com $36,1^{\circ} \mathrm{C}$ (quente-úmido) e $34,9^{\circ} \mathrm{C}$ (quente-seco), apresentado como percepção térmica de "calor" para os dois períodos, segundo Monteiro (2008). O PMV foi de 2,9 (período quente-úmido) e de 2,7 (período quente-seco) para o local sem sombreamento e para o sexo masculino, esses valores se enquadram no stress fisiológico igual a "forte stress ao calor".

\section{Questionário}

Para analisar as respostas dos entrevistados, as questões foram divididas em duas partes. A primeira contendo as questões A e B (Figura 6 e Figura 7) e a segunda contendo as questões C, D, E e F (Figura 8 e Figura 9).

As Tabela 3 e Tabela 4, informam o significado das legendas da Figura 6 a Figura 9.

\section{Tabela 3 - Significado das legendas das questões A e B}

\begin{tabular}{ccc}
\hline Legenda & $\begin{array}{c}\text { Questão A - Como você está } \\
\text { sentido nesse momento? }\end{array}$ & $\begin{array}{c}\text { Questão B - Com relação às } \\
\text { condições climática, você está se } \\
\text { sentido }\end{array}$ \\
\hline-2 & Muito frio & Desconfortável \\
-1 & Frio & Pouco desconfortável \\
0 & Nem frio, nem calor & Neutro \\
1 & Calor & Pouco confortável \\
2 & Muito calor & Confortável \\
\hline
\end{tabular}

$\mathrm{Na}$ questão A do período quente-úmido, a maior porcentagem das respostas nos três horários foi calor (1), na parte da tarde 30,65\% responderam estarem sentido muito calor (2). Na questão $\mathrm{B}$, a resposta confortável foi a maior em todos os horários, mostrando que mesmo com calor as pessoas se sentem confortáveis, ou seja, estão aclimatadas, conforme a Figura 6. 
Figura 6 - Resultado em porcentagem das respostas obtidas nas questões $A$ e $B$, no período quente-úmido

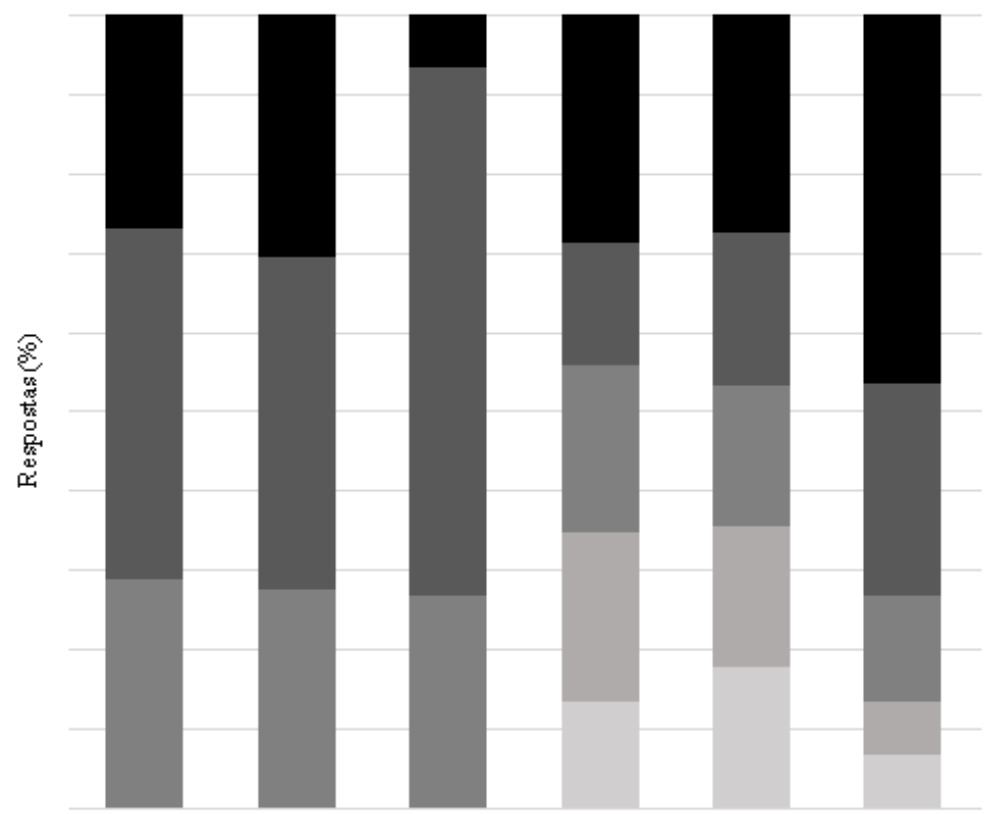

No período quente-seco (Figura 7) as maiores porcentagens de respostas foram "muito calor" (Questão A), no horário da tarde com 62,5\% e da noite com 66,67\%. Estes resultados reforçam que no período quente-seco os usuários se sentem desconfortáveis termicamente, ou seja, com muito calor.

Figura 7 - Resultado em porcentagem das respostas obtidas nas questões A e B, no período quente-seco

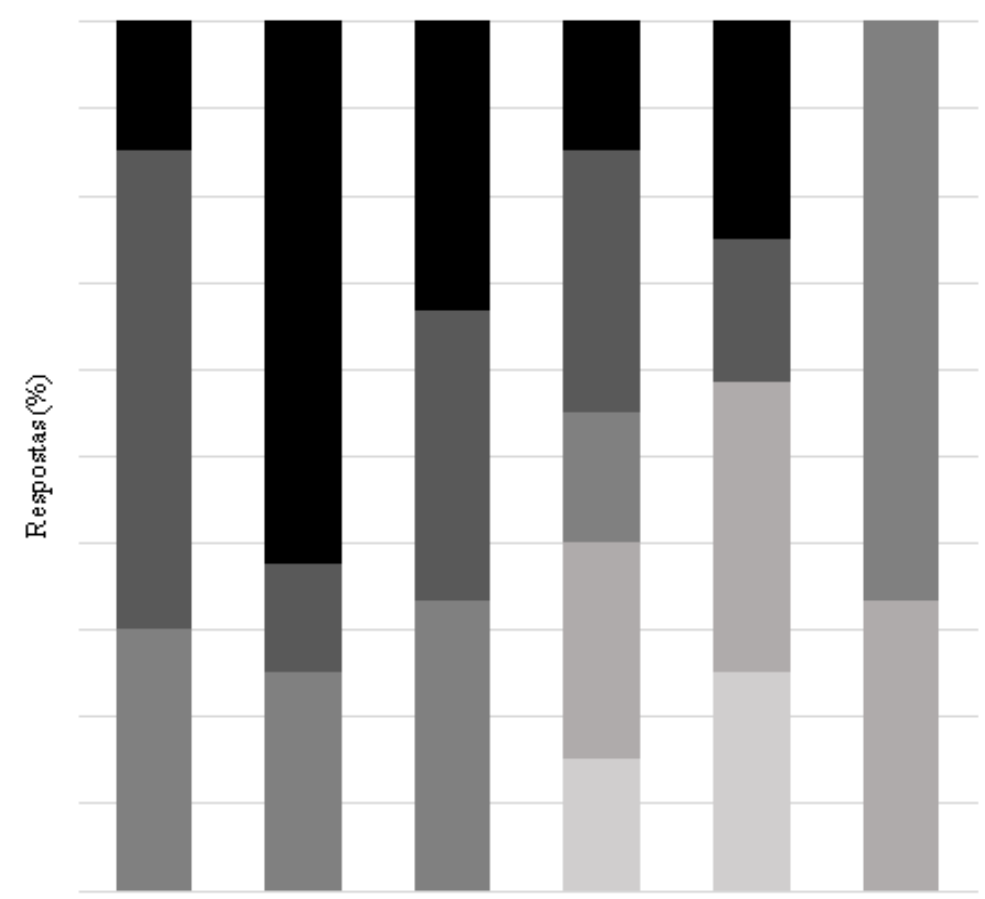


Na questão B as respostas tiveram variações entre "pouco confortável”, "pouco desconfortável” e "desconfortável”, diferentemente do período quente-úmido, em que as pessoas mesmo sentido "calor” estavam “confortáveis".

\section{Tabela 4 - Significado das legendas das questões C, D, E e F}

\begin{tabular}{ccccc}
\hline Legenda & $\begin{array}{c}\text { Questão C - } \\
\text { Em relação à } \\
\text { temperatura do } \\
\text { ar, você preferiria } \\
\text { que estivesse }\end{array}$ & $\begin{array}{c}\text { Questão D - Em } \\
\text { relação à umidade } \\
\text { do ar, você } \\
\text { preferiria que o ar } \\
\text { estivesse }\end{array}$ & $\begin{array}{c}\text { Questão E - Em } \\
\text { relação ao vento, } \\
\text { você preferiria } \\
\text { que estivesse }\end{array}$ & $\begin{array}{c}\text { Questão F - } \\
\text { Em relação à } \\
\text { radiação, você } \\
\text { preferiria que } \\
\text { estivesse }\end{array}$ \\
\hline-1 & Mais baixa & Mais seco & Mais fraco & Mais branda \\
0 & Como está & Como está & Como está & Como está \\
1 & Mais alta & Mais úmido & Mais forte & Mais intensa \\
NS & Não sei & Não sei & Não sei & Não sei \\
\hline
\end{tabular}

Pode-se notar na Figuras 8 e 9, que as maiores porcentagens de respostas das questões $\mathrm{C}$ e $\mathrm{F}$, foram referente à "-1" que significa , temperatura do ar "mais baixa” e radiação "mais branda". No período quente-úmido (Figura 8), as respostas oscilaram entre as respostas "como está", "mais úmido" e "mais forte", referentes a úmidade do ar e velocidade do vento.

\section{Figura 8 - Resultado em porcentagem das respostas obtidas nas questões C, D, E e F, no período quente-úmido}

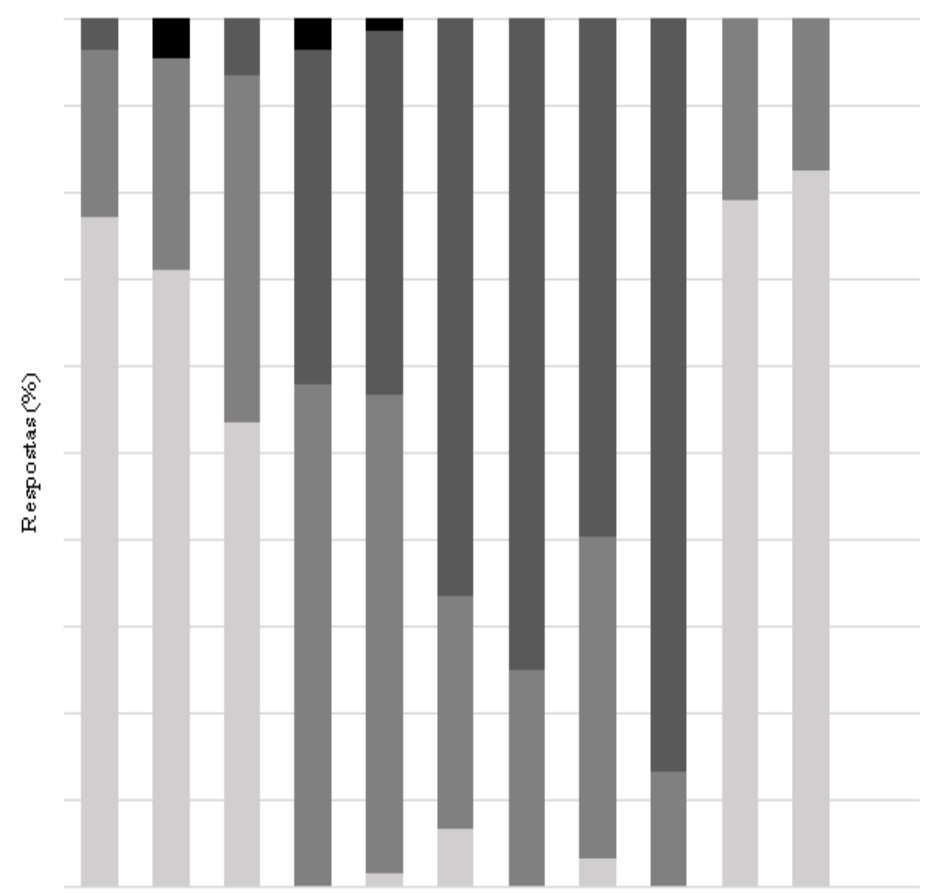

Na Figura 9, pode-se observa que na questão D, mais de 95\% das respostas formam “mais úmido" em relação a umidade do ar, mostrando que os entrevistados estavam desconfortáveis com a umidade, pois nesse período a umidade estava abaixo do valor recomendado pela Organização Mundial de Saúde (OMS), que é de 60\% de umidade do ar. 


\section{Figura 9 - Resultado em porcentagem das respostas obtidas nas questões C, D, E e F no período quente-seco}

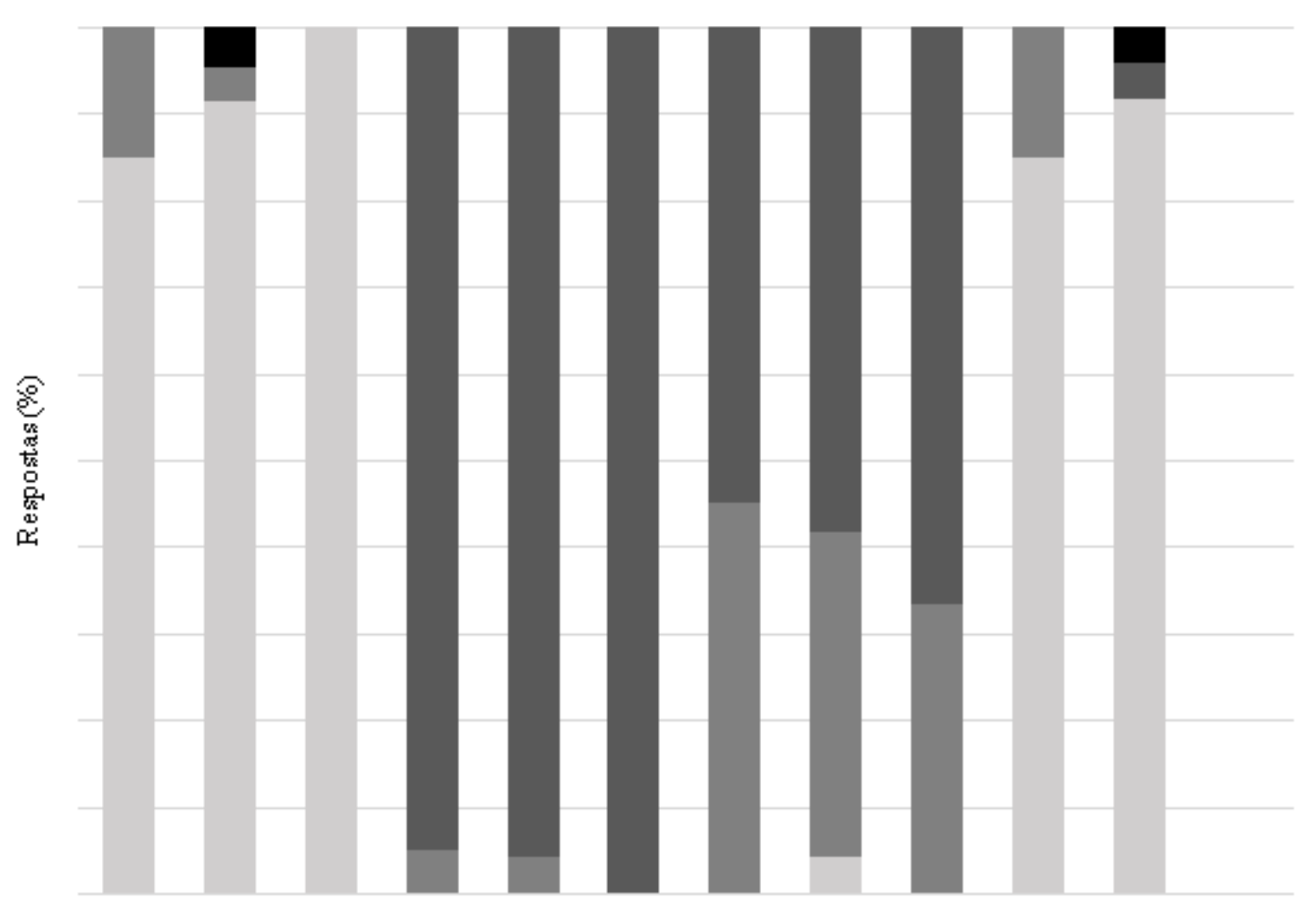

\section{Conclusão}

De acordo com os resultados, as maiores amplitudes registradas entre os cenários (oiti / mangueira / sem sombreamento) e os períodos (quente-seco / quente-úmido), na temperatura e a umidade do ar, ocorreram no horário da tarde, indicando a influência da radiação solar sob a superfícies que alteram o balanço de energia, gerando temperaturas diferentes entre os cenários. Já no horário da manhã e da noite as variações não obtiveram grandes magnitudes.

Nos índices de conforto térmico, não houve variações expressivas para os diferentes sexos calculados sendo que apenas no período noturno (20h) os valores do PET e PMV foram satisfatórios, alcançando a faixa de conforto térmico, em ambos os índices neste horário. Foi possível observar que no período quente-úmido, nos três horários analisados, os usuários sentiram calor, mas responderam estarem confortáveis, indicando o fato de estarem aclimatadas com as condições do clima na região. No período quente-seco, observa-se menor resistência dos usuários ao rigor climático pelo calor, demonstrando-se desconfortáveis com a condição climática do período.

Os resultados demostraram melhores desempenhos térmicos nas áreas com sombreamento arbóreo, reforçando a importância da arborização nas cidades para proporcionar melhor conforto térmico aos usuários. As contribuições e benefícios da utilização da arborização urbana são de estratégias de resfriamento evaporativo, umidificação, melhoramento do microclima e o seu entorno, que resultará em um ambiente externo mais atrativo e adequados ao uso, principalmente em região com temperatura elevadas. 


\section{Agradecimento}

Os autores agradecem a FAPEMAT pelo auxílio e apoio financeiro no desenvolvimento da pesquisa.

\section{Referência}

ALMEIDA JÚNIOR, N. L. Estudo de clima urbano: uma proposta metodológica. 2005. Dissertação (Mestre em Física e Meio Ambiente) - Universidade Federal de Mato Grosso, Cuiabá.

ALVES, E. D. L.; BIUDES, M. S. Padrões da temperatura do ar e da umidade relativa: estudo de caso no campus de Cuiabá da Universidade Federal de Mato Grosso. Boletim de Geografia, Maringá, v. 30, n. 3, p. 5 - 16, 2012.

BONAN, G. B., 1997: Effects of land use on the climate of the United States. Climatic Change, 37, 449-486.

CALlEJAS, I. J. A., DURANTE, L. C., DE OLIVEIRA, A. S., \& NOQUEIRA, M. C. D. J. A. Diversidade e índices arbóreos em ambientes escolares. Revista Eletrônica em Gestão, Educação e Tecnologia Ambiental, v. 18, n. 1, p. 454-466, 2014.

CALlEJAS, I. J. A., DURANTE, L. C., NOGUEIRA, M. C. J. A., NOGUEIRA, J. S., CAMPOS, A. C. S. Estudo do sombreamento arbóreo, atenuação da radiação solar e microclima dos pátios escolares: elementos para se pensar a sustentabilidade urbana. In: IV Encontro Latino-americano sobre Edificações e Comunidades Sustentáveis, 2011, Vitória. Anais... Vitória, 2011.

CALLEJAS, I. J.; CAMPOS, A. C.; DURANTE, L. C.; NOGUEIRA, M. C. Índices arbóreos e suas relações com o microclima urbano. In: ENCONTRO NACIONAL DE TECNOLOGIA DO AMBIENTE CONSTRUÍDO, 14, 2012, Juiz de Fora. Anais eletrônicos... Juiz de Fora: UFJF, 2012. Disponível em: < http://www.infohab.org.br/ entac2014/2012/docs/1000.pdf>. Acesso em 15 de jun. 2015.

COX, E. P. Interação entre clima e superfície urbanizada: o caso da cidade de Várzea Grande/MT. Cuiabá, 2008. 141p. Dissertação (Mestrado em Física e Meio Ambiente) - Departamento de Física, Instituto de Ciências Exatas e da Terra, Universidade Federal de Mato Grosso.

DURANTE, L.; NOGUEIRA, M. C. J. A. Efeitos do sombreamento arbóreo nas condições termo-higrométricas e lumínicas de ambientes internos e externos de edificações. Revista Eletrônica em Gestão, Educação e Tecnologia Ambiental, Santa Maria, v. 9, n. 9, p. 1980 - 1998, 2013. 
FRANCO, F.M. Configuração urbana e sua interferência no microclima local: estudo de caso no bairro do porto em Cuiabá-MT.2010.153f. Dissertação (Mestrado em Ambiental), Instituto de Física, Universidade Federal de Mato Grosso.

GOMES, M. A. S.; SOARES, B. R. A vegetação nos centros urbanos: considerações sobre os espaços verdes em cidades médias brasileiras. Estudos Geográficos, Rio Claro. v. 1, n. 1, p. 29-39, 2003.

KULKA, D. D. Conforto Térmico em Áreas Verdes Urbanas no Município de Itapetinga, Bahia. 72f. Dissertação (Mestrado em Ciências Ambientais. Área de Concentração: Meio Ambiente e Desenvolvimento), Universidade Estadual do Sudoeste da Bahia, Itapetinga, Bahia, 2014.

LOUREIRO, V. R.; BARBOSA, E. J. S. Cidade de Belém e natureza: uma relação problemática? Periódicos UFPA, Belém, v. 13, n. 1, p. 105 -134, 2010.

MACIEL, C. R.; NOGUEIRA, M. C. J. A.; NOGUEIRA, J. S. Cobertura do solo e sua influência na temperatura de microclimas urbanos na cidade de Cuiabá - MT. Caminhos de Geografia, Uberlândia, v. 12, n. 39, p. 40 - 57, 2011.

MATZARAKIS, A.; MAYER, H.; IZIOMON, M. G. Applications of a universal thermal index: physiological equivalent temperature. International Journal of Biometeorology, v. 43, p. 76-84, 1999. Disponível em <http://www.urbanclimate.net/matzarakis/papers/ pet_aplication.pdf> Acesso em 25 out. 2015.

MONTEIRO,L.M.; ALUCCI,M.P. Comparação cruzada entre pesquisas loboratoriais e de campo em conforto térmico em espaços abertos urbanos. Ambiente Construído, Porto Alegre, v.10,n.4p.79-101,out./dez.2010.

MORENO, M. M. Parâmetros para implementação efetiva de áreas verdes em bairros periféricos de baixa densidade. 2006.147p. Dissertação (Mestrado em Engenharia Civil) - Universidade Estadual de Campinas, São Paulo, 2006.

NINCE, P. C. C. Vegetação e revestimentos urbanos: Implicações na Sensação Térmica dos usuários do Campus da UFMT em Cuiabá - MT. 2013. Dissertação (Doutorado em Física Ambiental), Instituto de Física, Universidade Federal de Mato Grosso, Cuiabá, 2013.

NINCE, P. C. do C.; SANTOS, F. M. de M.; NOGUEIRA, J. de S.; NOGUEIRA, M. C. D. J. A. Conforto térmico dos usuários em vegetação e revestimentos urbanos no campus da UFMT em Cuiabá-MT. Revista Monografias Ambientais, v. 13, n. 4, 2014.

NOWAK, D. J.; KEVIN, L. C.; RAO, S. T.; SISTLA, G.; LULEY, C. J.; CRANE, D. E. A modeling study of the impact or uban trees on ozone. Atmospheric environment, New York, v. 34, p. 1601-1613, 2000. 
OLIVEIRA, A. S. Influência da vegetação arbórea no microclima e uso de praças públicas. Cuiabá, 2011.146f. Tese (Doutorado) - Programa de Pós-graduação em Física Ambiental, Universidade Federal de Mato Grosso.

OLIVEIRA, G. S. J. F.; QUEIROZ, M. T. A.; PAGIOLA, R. G.; FERREIRA, W. L. Conforto térmico no ambiente de trabalho: avaliação das variáveis subjetivas da percepção do calor. VII Simpósio de Excelência em Gestão e Tecnologia-CRA-RJ, Rio de Janeiro, Brasil, 2010.

ORTOLANI, C.; VITALE, M. The importance of local scale for assessing, monitoring and predicting of air quality in urban areas. Sustainable Cities and Society, 2016. (http:// www.sciencedirect.com/science/article/pii/S221067071630107X)

PEREIRA, A. R.. Agrometeorologia: fundamentos e aplicações práticas. Guaíba: Agropecuária, 2002.

SANTOS, F.M.M.;MUSIS, C.R., NOGUEIRA, S.J.;JÚNIOR, O. B.P.; NOGUEIRA, M.C.D.J.A. Análise da variação higrotérmica ocasionada pela influência da ocupação do solo na cidade de Cuiabá - MT. Revista Eletrônica em Gestão, Educação e Tecnologia Ambiental, Santa Maria, v. 9, n. 9, p. 1932 - 1945, 2013.

TAKÁCS, Á.; KISS, M.; HOF, A.; TANÁCS, E.; GULYÁS, Á.; KÁNTOR, N. Microclimate Modification by Urban Shade Trees-An Integrated Approach to Aid Ecosystem Service Based Decision-making. Procedia Environmental Sciences, v. 32, p. 97-109, 2016.

VALIN JR, M. O.; SANTOS, F. M. M.; RIBEIRO, K. F. A.; NOGUEIRA, M. C. J. A.; NOGUEIRA, J. S.. Análise da relação entre abrigos meteorológicos alternativos para pontos fixos e o comportamento de variáveis termo-higrométricas. Revista Brasileira de Climatologia, v. 18, p. 157-179, 2016.

YANG, Z. L.; DAI, Y.; DICKINSON, R. E.; SHUTTLEWORK, W. J. Sensitivity of ground heat flux to vegetation cover fraction and leaf area index. Journal of Geophysical Research, v. 104, n. D16, p. 19,505-19,514, August 27, 1999. 